\title{
REVIEW
}

\section{Paraneoplastic Syndromes Associated with Laryngeal Cancer}

\author{
Alessandra Rinaldo · Andrés Coca-Pelaz $\cdot$ Carl E. Silver · \\ Alfio Ferlito
}

Received: September 27, 2019 / Published online: December 4, 2019

(C) The Author(s) 2019

\section{ABSTRACT}

Objectives: Paraneoplastic syndromes occur rarely in association with laryngeal cancer. When present, the syndrome may be the first sign of the malignancy. The aim of the present study was to review and report on all published cases in the international literature.

Methods: A search of PubMed was conducted for "paraneoplastic syndromes in laryngeal

This article was written by members of the International Head and Neck Scientific Group (http://www.IHNSG. com).

Enhanced Digital Features To view enhanced digital features for this article go to https://doi.org/10.6084/ m9.figshare. 10303700 .

\section{A. Rinaldo}

University of Udine School of Medicine, Udine, Italy

A. Coca-Pelaz

Department of Otolaryngology, Hospital

Universitario Central de Asturias, Oviedo, Spain

A. Coca-Pelaz

Instituto de Investigación Sanitaria del Principado

de Asturias, IUOPA, CIBERONC, Oviedo, Spain

C. E. Silver

Department of Surgery, University of Arizona

College of Medicine, Phoenix, AZ, USA

\section{A. Ferlito $(\square)$}

International Head and Neck Scientific Group,

Padua, Italy

e-mail: a.ferlito@uniud.it cancer" without any restrictions on language or publication year. The full texts of all relevant articles were reviewed and all cases of paraneoplastic syndromes associated with any type of laryngeal cancer were extracted and analyzed.

Results: We identified 59 cases of paraneoplastic syndromes related to laryngeal cancer in the literature published from 1963 until recently. There were 46 squamous cell carcinomas and 10 neuroendocrine carcinomas. Twenty-two of the paraneoplastic syndromes involved the endocrine system, 21 were dermatologic or cutaneous, 8 neurologic, 5 osteoarticular or rheumatologic, 1 ocular, 1 muscular, and 1 hematologic. Treatment strategies included surgery, radiotherapy, chemotherapy, and often multimodal therapy, depending on the histology and stage of the laryngeal cancer.

Conclusions: Because of their rarity, paraneoplastic syndromes associated with laryngeal cancer are difficult to diagnose. By presenting and systematically reviewing all published cases in the international literature, the present review may help clinicians to recognize them and to suspect the diagnosis of laryngeal cancer at an earlier stage than otherwise might be possible.

Keywords: Cancer of the larynx; Diagnosis; Larynx; Metastasis; Paraneoplastic syndromes; Recurrence 


\section{Key Summary Points}

Paraneoplastic syndromes occur rarely in association with laryngeal cancer.

When present, the syndrome may be the first sign of the malignancy.

A search of PubMed was conducted for "paraneoplastic syndromes in laryngeal cancer".

Paraneoplastic syndromes associated with laryngeal cancer are difficult to diagnose.

Recognizing a paraneoplastic syndrome helps in suspecting a laryngeal cancer.

\section{INTRODUCTION}

The symptoms and signs of various cancers are caused by the effects of the neoplasm locally, regionally, or distantly. In a few patients, these signs and symptoms are not directly produced by the primary tumor or its metastases, appearing rather to be produced by other, perhaps humoral, but often not fully understood mechanisms. These conditions are called "paraneoplastic syndromes" and their location does not coincide with the site of tumor [1-3]. Paraneoplastic syndromes are rare clinical syndromes due to the systemic effects of tumors; they are unrelated to tumor size, invasiveness, or metastases [4]. A paraneoplastic syndrome may be the first indication of an underlying cancer (initial, persistent or recurrent tumor, or asymptomatic metastasis). It is not due to direct organ invasion but is caused by substances elaborated by the distant neoplasm. These syndromes may precede the presentation of a cancer by many months, occasionally by several years. Whatever hormones and/or antibodies produce these syndromes, they share the property of acting far from their site of synthesis [5].

Other terminology for paraneoplastic syndromes includes paraneoplastic conditions, paraneoplastic effects, paraneoplastic events, non-metastatic syndromes, paraneoplastic phenomena, paraneoplastic disturbances, or remote effects. Paraneoplastic syndromes are more often recognized at the present time than previously, because of improving diagnostic methods and greater current knowledge about them among clinicians [6-9].

Small cell lung cancer is the tumor most frequently associated with these syndromes, although they can occur in almost any type of malignant tumor [10].

Laryngeal cancers, regardless of histology, have rarely been associated with paraneoplastic syndromes [1, 2, 11-13]. In this manuscript we will group these syndromes into seven headings: (1) dermatologic or cutaneous, (2) endocrine, (3) hematologic, (4) neurologic, (5) osteoarticular or rheumatologic, (6) ocular, and (7) muscular.

This article is based on previously conducted studies and does not contain any studies with human participants or animals performed by any of the authors.

\section{METHODS}

In order to identify all published cases of paraneoplastic syndromes associated with laryngeal cancer, we performed a review of the more relevant articles that cover this issue. For this purpose, the Preferred Reporting Items for Systematic Review and Meta-Analyses (PRISMA) method was used to conduct a systematic review of the current literature [14]. A PubMed internet search updated to March 3, 2019 was performed for publications using the following search terms in the title or abstract: "paraneoplastic syndrome" coupled with "head and neck cancer" or "larynx cancer". The search results were reviewed for potentially eligible studies. When the abstract indicated that the article included a report of a paraneoplastic syndrome, the full-text article was searched and reviewed in order to know if the tumor was located in the larynx, excluding primary tumors at any other sites (e.g., hypopharynx). All articles were checked in full text for cross-references. References from full-text articles were cross-checked to ensure inclusion of all relevant publications in this review. Selected studies met the following inclusion criteria: (1) patients diagnosed with a 
paraneoplastic syndrome, (2) location of the tumor specified in the text within the larynx. Studies in which the location of the primary tumor was not specified clearly, or which were referred to as located in the larynx but were located in the pyriform sinus were excluded.

\section{RESULTS}

\section{Selection of Included Studies}

The initial search identified 174 original articles, 42 of which were excluded on the basis of the aforementioned search criteria. Full texts of the remaining 132 studies were assessed. Of these, 85 articles were excluded as they did not include cases of laryngeal cancer with paraneoplastic syndromes, or the primary site was not specifically defined. This selection process resulted in the final inclusion of 47 articles (Fig. 1).

\section{Description of Included Cases}

In the selected articles, we identified in total 59 cases of paraneoplastic syndromes related to laryngeal cancer in the published literature from 1963 until recently. The average age of the patients was 61.55 years (median 61.5 years, range 45-78 years); age was unknown in 19 cases. There were 36 men and 7 women (16 gender not stated). In 18 cases the primary tumor was supraglottic, 12 cases glottis, and 1

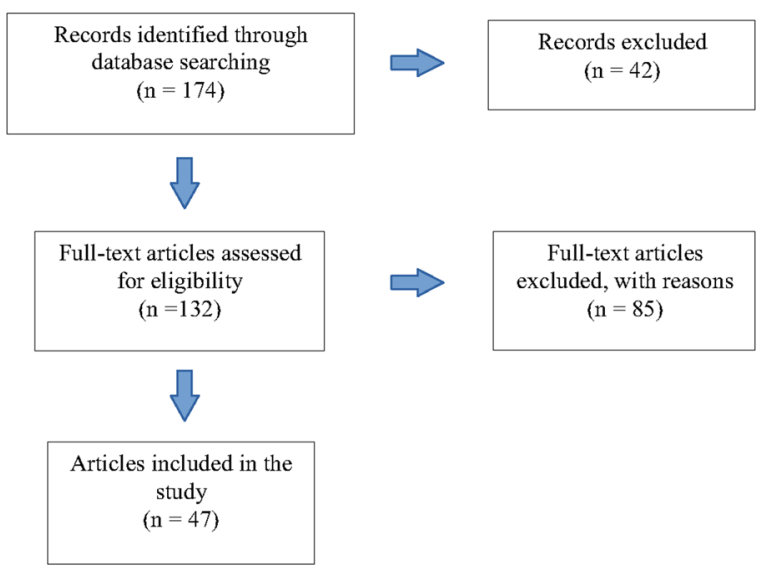

Fig. 1 Flow chart showing the process of the study selection for the systematic review subglottic (28 not stated). Histology was not mentioned in 3 cases. Most of the identified laryngeal cancers were squamous cell carcinoma $(n=46)(46 / 56: 82.1 \%)$ followed by neuroendocrine carcinoma $(n=10) \quad(10 / 56: 17.9 \%)$. Endocrine $(n=22)$ and dermatologic or cutaneous $(n=21)$ paraneoplastic syndromes were the most prevalent, followed by neurologic $(n=8)$, osteoarticular or rheumatologic $(n=5)$, ocular $(n=1)$, muscular $(n=1)$, and hematologic $(n=1)$ syndromes. Applied treatment strategies included surgery, radiotherapy, chemotherapy, and often multimodal therapy, according to the site and stage of the tumors. Twenty-eight patients underwent surgery for the treatment of the primary tumor that caused the paraneoplastic syndrome, 23 received radiotherapy, 11 patients were treated with chemotherapy, and 20 patients underwent different multimodal treatment for their condition. Survival outcome differed highly among the published cases; 19 patients were alive, and 23 patients had died of disease at the times of publication. However, the value of these survival data is questionable as follow-up data are very often not included in the original articles or the follow-up time is very short.

\section{LITERATURE REVIEW WITH DISCUSSION}

\section{Paraneoplastic Dermatologic or Cutaneous Syndromes}

Several paraneoplastic dermatologic or cutaneous syndromes have been reported [15]. Acanthosis nigricans, Bazex syndrome, bullous pemphigoid, dermatomyositis, yellow nail syndrome, tylosis, pityriasis rubra pilaris, and Leser-Trélat sign were observed in various patients with laryngeal cancer.

\section{Acanthosis Nigricans}

Acanthosis nigricans is a cutaneous condition characterized by hyperpigmented papillomatous plaques that usually affects flexor areas symmetrically, but it can be seen in any part of the body. When related to a malignant tumor, 
the condition appears abruptly, with rapid and extensive progression. The most frequently experienced association is with abdominal adenocarcinoma (60\% are stomach cancer), but there have been cases associated with laryngeal tumors [16].

\section{Bazex Syndrome}

Bazex syndrome (also named Bazex's acrokeratosis paraneoplastica, acrokeratosis paraneoplastica, acrokeratosis Bazex) is clinically characterized by erythematous squamous eruptions that spread centripetally from the fingertips and toes, ears, nose, and other sites.

Occasionally, vesicles, bullae, and crusts have been described. Symmetrical distribution is the norm. This syndrome has most often been associated with malignant tumors located above the diaphragm, and is most commonly associated with head and neck cancers (oral cavity, pharynx, larynx, and others) with nodal involvement $[17,18]$. It has also been associated with cancers from other locations (including bronchus, thymus, prostate, uterus) and with different histologic types (myeloma, adenocarcinoma, anaplastic carcinoma, and others) [19].

Bazex's acrokeratosis is the most frequent paraneoplastic syndrome associated with tumors located in the larynx [17, 19-30]. Occasionally, other cutaneous paraneoplastic syndromes (Bazex syndrome, hyperpigmentation, and acquired ichthyosis) have been reported in patients with larynx cancer [21].

In some cases, laryngeal cancer had been diagnosed because of the appearance of a cutaneous paraneoplastic syndrome [31, 32].

\section{Bullous Pemphigoid}

Bullous pemphigoid is a common autoimmune blistering disorder of the skin and has been observed in patients with various malignant tumors, although the significance of this association is controversial [33]. Some studies show an obvious association between malignancies and bullous pemphigoid, but other studies have failed to demonstrate a higher risk of malignancies among patients with bullous pemphigoid. The question remains whether in these cases bullous pemphigoid is a paraneoplasia or a coincidental association. Currently, it is suggested that the term "paraneoplastic pemphigoid" be avoided. "Pemphigoid associated with malignancies" is preferred [34].

\section{Dermatomyositis}

Dermatomyositis is an idiopathic inflammatory disease that can produce degenerative and inflammatory damage to muscle and skin in a symmetrical and progressive way. Despite its unknown cause, it has been associated with different tumors (lung, larynx, breast, and others) $[35,36]$.

\section{Yellow Nail Syndrome}

Yellow nail syndrome has been reported in patients affected by larynx cancer. The syndrome always regressed after treatment of the tumor [37]. The syndrome is characterized by nail discoloration and is associated with lymphedema (considered secondary to anomalies of lymphatic drainage), and also with bronchiectasis and sinusitis.

\section{Tylosis}

Tylosis, or hyperkeratosis, occurs on the palms of the hands (palmarum) or the plantar region of the foot (plantarum). Esophageal and, less commonly, laryngeal cancer may occur in association [38]. This disorder is considered paraneoplastic.

\section{Pityriasis Rubra Pilaris}

Pityriasis rubra pilaris constitutes a cluster of papulosquamous dermatoses often confused with various skin disorders (psoriasis in particular). This disease possibly results from dysregulation of the immune system as well as unusual response to certain antigens associated with rheumatological diseases, trauma and infections (human immunodeficiency virus), hypothyroidism, and solid and hematological malignancies. The syndrome has occurred in cases of laryngeal cancer [39].

\section{Leser-Trélat}

The Leser-Trélat sign, characterized by the sudden occurrence of multiple seborrheic keratoses, often with associated pruritus, is 
considered a marker of internal malignancy. Acanthosis nigricans can occur in $20 \%$ of such cases. The most frequently reported malignancies associated with the Leser-Trélat sign are stomach cancer, lymphoma, and gastrointestinal adenocarcinoma. There are also reports of occurrence in cases of laryngeal cancer [40].

\section{Paraneoplastic Endocrine Syndromes}

Production of polypeptide hormones is the causative factor in paraneoplastic endocrine syndromes related to lung, breast, carcinoids, and thyroid medullary cancer.

\section{Carcinoid Syndrome}

Carcinoid syndrome (carcinoidosis or argentaffinosis) most often is associated with metastatic neuroendocrine neoplasms (lung, gastrointestinal tract, ovary, etc.) [41-43]. The four major components of this syndrome are episodic diarrhea, skin flushing, affecting the face and the upper trunk, carcinoid heart disease, and bronchospasm. Dermatitis and depression occur less commonly. Some patients can manifest all of the above symptoms.

Most neuroendocrine malignancies of the larynx reported in the literature were nonfunctional and, therefore, without clinical syndromes [1, 12, 44, 45]. Five cases of laryngeal neuroendocrine carcinomas (one well differentiated, one large cell, and three moderately differentiated) with a carcinoid syndrome were reported [46-50]. The case described by Overholt et al. [48] as moderately differentiated neuroendocrine carcinoma has recently been considered to have been a large cell neuroendocrine carcinoma (Leon Barnes and James S. Lewis Jr., personal communication, 2019).

Nine of the ten patients affected by a paraneoplastic syndrome [carcinoid syndrome, Schwartz-Bartter syndrome, Eaton-Lambert syndrome, adrenocorticotropic hormone (ACTH) syndrome] died. Only one patient was alive with disease after 42 months of follow-up [13].

\section{Ectopic ACTH Syndrome}

Ectopic ACTH syndrome was reported in association with a larynx cancer by Imura et al. [51].
Bishop et al. [52] reported on the first case of small cell neuroendocrine carcinoma of the larynx associated with ectopic ACTH syndrome. The cell cytoplasm was immunoreactive for ACTH, gastrin-releasing polypeptide, neuron-specific enolase, $\beta$-endorphin, calcitonin, and keratin, by indirect immunoperoxidase techniques.

\section{Schwartz-Bartter Syndrome}

Schwartz-Bartter syndrome (syndrome of inappropriate secretion of antidiuretic hormone, SIADH) was first described by Schwartz et al. [53] in two patients with bronchogenic carcinoma. The syndrome is characterized by ectopic synthesis and excretion of vasopressin by cancer cells that leads to impaired excretion of free water, water intoxication, and hyponatremia. The reduced sodium level is due both to an enlarged amount of extracellular fluid and to its higher urinary excretion.

In the head and neck, SIADH is a well-known form of paraneoplastic syndrome. In a review by Ferlito et al. [11], 70 cases of this syndrome were found to be associated with head and neck cancers. Oral cavity was the commonest location of the primary tumor (29 cases). Thirteen cases involved the larynx. Squamous cell carcinoma was the predominant histology [54-58]. Three cases were small cell neuroendocrine carcinoma [59-61]. SIADH may precede the diagnosis of the cancer by several months.

Patients may present with initial headache, confusion and temporo-spatial disorientation, hyperreflexia, reduced levels of sodium, chlorine and osmolarity, decreased hematocrit, negative free-water clearance, and elevation of antidiuretic hormone. These tumors appear to have a very poor prognosis, as all these patients died despite adequate therapy.

\section{Hypercalcemia}

Hypercalcemia, which is the most frequently occurring metabolic complication of malignancy [62], often occurs during the late stages of malignancy. Hypercalcemia is a complication of many advanced tumors including carcinomas of the ovary, kidney, esophagus, and the head and neck, hematopoietic malignancies, and solid sarcomas $[63,64]$. An uncommon cause is bone metastasis 
[65]. Many tumors cause hypercalcemia due to inappropriate hormonal regulation. Patients with laryngeal cancer often have hypercalcemia in the absence of metastasis [65]. Parathyroid hormonerelated protein (PTHrP) is not confined to malignancy-associated hypercalcemia, and sufficient evidence now also supports its role in skeletal metastasis (through its modulation of bone turnover), as well as in tumor progression and metastasis [66]. Clinical signs of mild hypercalcemia include anorexia, constipation, abdominal pain, nausea and vomiting, thirst with polyuria, myalgias, weakness, fatigue, headaches, depression, and confusion. Hypercalcemia is a medical emergency [67]. Hypercalcemia associated with advanced malignancy portends a dismal prognosis. Hypercalcemia is managed by treatment of the cancer responsible for it [67].

\section{Paraneoplastic Hematologic Syndromes}

Paraneoplastic hematologic syndromes are more commonly associated with other malignancies than cancer of the larynx.

\section{Trousseau Syndrome}

Trousseau syndrome (disseminated intravascular coagulation or thromboembolism) was first reported by Armand Trousseau [68]. Trousseau described thrombotic events related to gastric cancer. Trousseau syndrome has been related to cancer of the pancreas, and occurred with ovarian, lung, colon, and breast cancer [69]. This syndrome is rare (less than 1\% [70]) in head and neck cancers, although it has occurred in patients with laryngeal cancer [71]. It is diagnosed by the findings of thrombocytosis and elevated fibrin levels. Thrombosis of unknown cause may be the first manifestation of cancer [72, 73].

\section{Paraneoplastic Neurologic Syndromes}

Paraneoplastic neurologic syndromes frequently occur in cancer patients, but they are uncommon when the primary site is the larynx.

\section{Cerebellar Degeneration}

Cerebellar degeneration, or cerebellar cortex degeneration, may be associated with lung, ovary, and breast cancer [2], and occasionally with larynx cancer $[74,75]$. It is primarily characterized by a wide-legged, unsteady, lurching walk accompanied by a back and forth tremor in the trunk and the body. Slow, unsteady, and jerky movement of the arms or legs, slowed and allured speech, and nystagmus may also be observed. The cause may be immunologic cross-reactions, and antineural antibodies, that are found in about $50 \%$ of the patients [6, 76]. The better known paraneoplastic neurologic syndromes are those with specific antibodies associated, and the clinical signs of these syndromes can precede clinical signs of the cancer [77].

\section{Ataxia}

Ataxia as a manifestation of cerebellar involvement is infrequent among the neurological manifestations of paraneoplastic syndromes and histologically usually corresponds to a diffuse massive loss of Purkinje cells, with little alteration of the white substance and frequent inflammatory signs. Clinically, it is manifested by a nonspecific cerebellar pattern with instability and dissymmetry that sometimes incorporates vestibular signs (spontaneous nystagmus). Garcia et al. [78] published a case of paraneoplastic ataxia due to a supraglottic larynx cancer. After surgery, ataxia was resolved within 3 weeks.

\section{Eaton-Lambert Myasthenic Syndrome}

Eaton-Lambert myasthenic syndrome was reported by Lambert et al. [79]. The complete syndrome was further delineated by Eaton and Lambert $[57,80]$. The same disease had previously been described by Gray and Halton [81]. It is usually associated with small cell lung cancer [82], but also with larynx cancer [83-86]. As with cerebellar degeneration, the detection of serum and cerebrospinal fluid autoantibodies can be helpful for diagnosis.

\section{Encephalomyelitis}

Encephalomyelitis has been considered as a paraneoplastic syndrome associated with small cell lung cancer $[7,87]$. There is abundant evidence in the literature that the anti-Hu 
antibody is a marker of encephalomyelitis [7]. Two cases of laryngeal cancer have been associated with this syndrome $[88,89]$.

\section{Paraneoplastic Osteoarticular or Rheumatologic Syndromes}

Paraneoplastic osteoarticular or rheumatologic syndromes occur rarely in laryngeal cancer and small cell lung carcinomas.

\section{Polyarthritis}

Polyarthritis has been associated with different cancers, both solid and hematological, and may be the earliest presentation of the malignancy. A neoplastic cause must be ruled out in any case of recently appearing polyarthritis [90]. Eggelmeijer and Macfarlane [91] reported an instance of larynx cancer associated with polyarthritis.

\section{Pseudo-Still Disease}

Cabane et al. [92] reported on an instance of aryepiglottic fold carcinoma in association with pseudo-Still disease, which is an inflammatory type of arthritis distinguished by pain, swelling, and tenderness in one or more joints along with splenic enlargement and lymphadenopathy.

\section{Hypertrophic Osteoarthropathy}

The syndrome of hypertrophic osteoarthropathy is distinguished by "clubbing" of the digits of the hand and/or foot, periosteal reaction, and arthralgia or arthritis which is the same syndrome associated with cyanotic congenital heart disease and chronic pulmonary infections. It may also occur in patients with carcinoma of the lung (particularly squamous cell carcinoma). Mackenzie and Scherbel [36] and Cohen [93] described three instances of this syndrome in patients with cancer of the larynx.

\section{Paraneoplastic Ocular Syndromes}

Paraneoplastic ocular syndromes are distinguished by progressive functional loss of photoreceptors and subsequent painless loss of vision, light-induced glare, night blindness, photosensitivity, and peripheral ring-like scotomas. Fundoscopic examination may be normal or might reveal arteriolar narrowing. The electroretinogram reveals abnormal cone and rod-mediated signals [94].

\section{Cancer-Associated Retinopathy (CAR)}

and Melanoma-Associated Retinopathy (MAR)

The most frequently occurring paraneoplastic ocular syndromes are cancer-associated retinopathy (CAR) and melanoma-associated retinopathy (MAR). Parc et al. [95] reported on CAR syndrome in a patient who complained of photophobia and bilateral visual loss who had a laryngeal cancer extirpated 18 months previously.

\section{Paraneoplastic Muscular Syndromes}

Paraneoplastic muscular syndromes like polymyositis are idiopathic inflammatory myopathies linked with cancer, but less frequent than dermatomyositis. Both conditions, polymyositis and dermatomyositis, present with proximal, symmetric muscle weakness. Clinical features along with raised creatine phosphokinase (CPK) and positive muscle biopsy are required for diagnosis. According to Hill et al. [96] about 30\% of dermatomyositis and $15 \%$ of polymyositis patients were found to have associated cancer, with approximately $60 \%$ of the malignancies diagnosed after the onset of myopathy. Most were detected within 1 year of presentation of myositis and the type of cancer most often associated was adenocarcinoma. Associated carcinomas observed in previous studies were ovarian, lung, cervical, pancreatic, stomach, colorectal, and nonHodgkin's lymphoma.

Sahu et al. [97] reported a case of a laryngeal cancer associated with polymyositis. With the treatment of the laryngeal cancer, the patient achieved almost normal muscle strength with normalization of CPK level after 6 months.

Table 1 summarizes paraneoplastic syndromes reported to have occurred in patients with cancer of the larynx $[16,17,23,26,27$, $30,33,35-40,46-52,55-61,65,71,75,78,83-$ $86,88,89,91-93,95,97-102]$. 


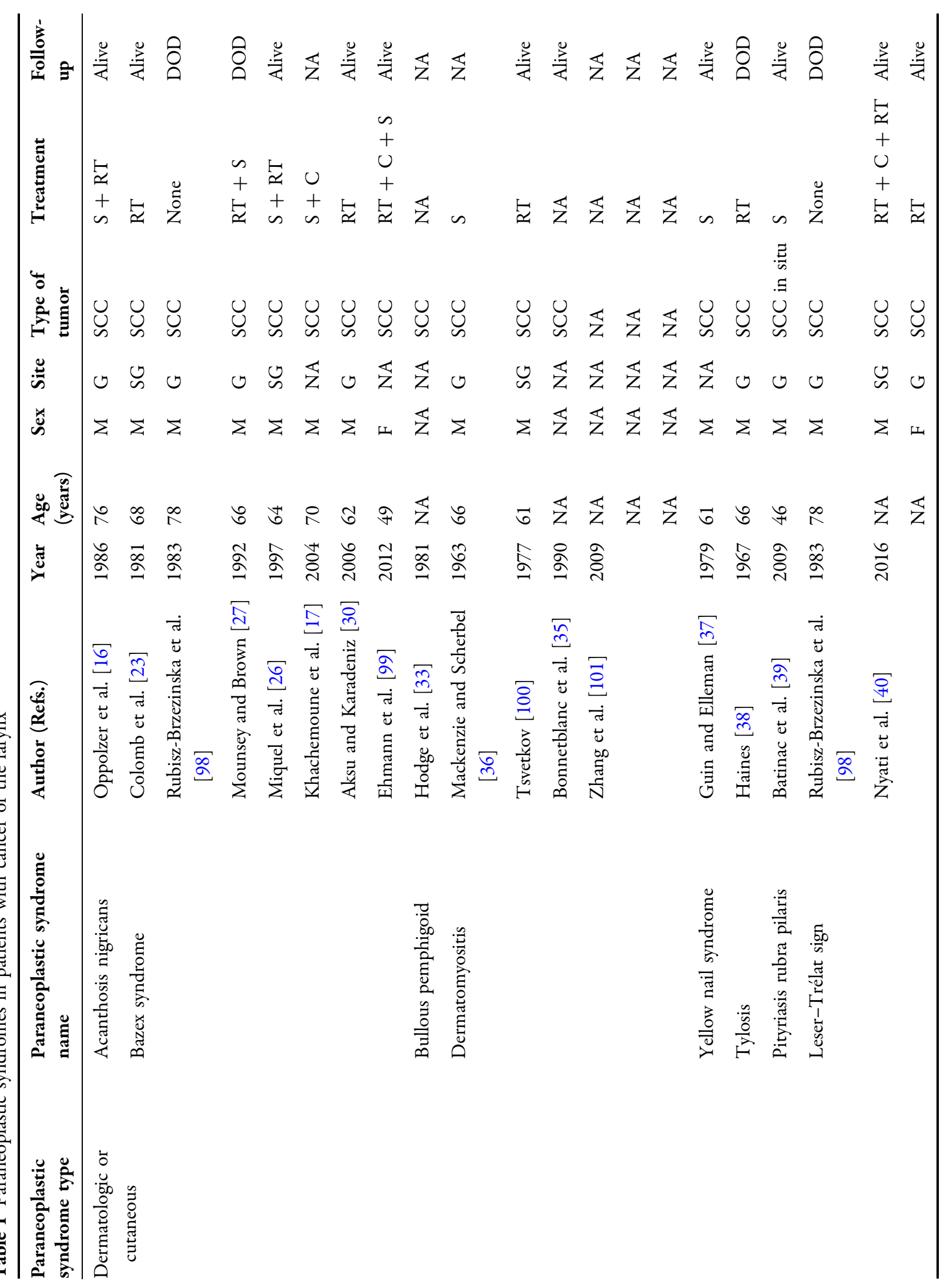




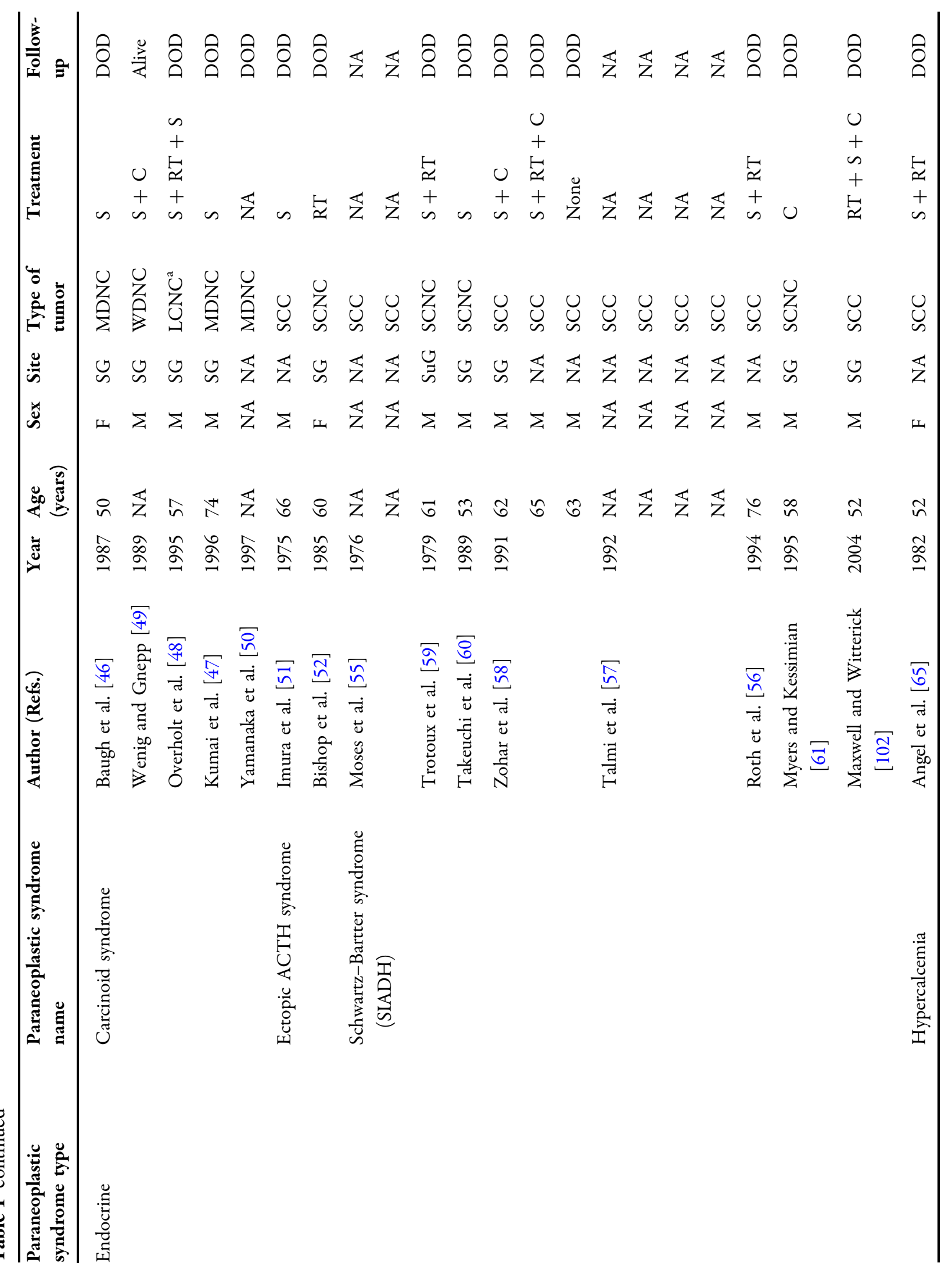




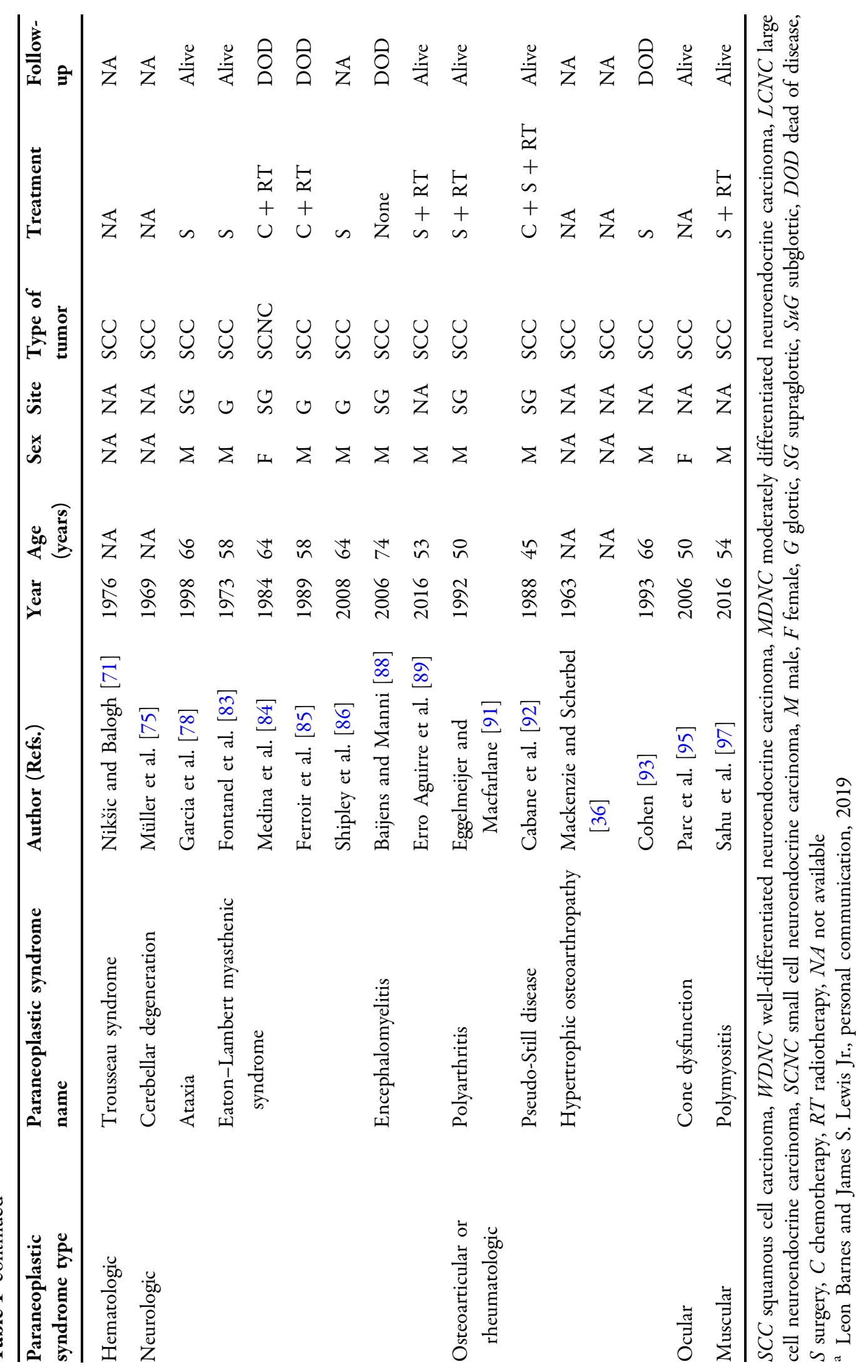




\section{CONCLUSIONS}

Paraneoplastic syndromes in laryngeal cancer occur infrequently and therefore are difficult to diagnose. The histology most frequently associated with paraneoplastic syndromes was squamous cell carcinoma and the most frequent location was supraglottic. By presenting and systematically reviewing all published cases in the international literature, the present review may help clinicians to recognize them.

\section{ACKNOWLEDGEMENTS}

Funding. No funding or sponsorship was received for this study or publication of this article.

Authorship. All named authors meet the International Committee of Medical Journal Editors (ICMJE) criteria for authorship for this article, take responsibility for the integrity of the work as a whole, and have given their approval for this version to be published.

Disclosures. Andrés Coca-Pelaz and Carl E. Silver have nothing to disclose. Alessandra Rinaldo and Alfio Ferlito are both members of this journal's Editorial Board but have no other relevant conflicts of interest to disclose.

Compliance with Ethics Guidelines. This article is based on previously conducted studies and does not contain any studies with human participants or animals performed by any of the authors.

Data Availability. All data generated or analyzed during this study are included in this published article.

Open Access. This article is distributed under the terms of the Creative Commons Attribution-NonCommercial 4.0 International License (http://creativecommons.org/licenses/ by-nc/4.0/), which permits any noncommercial use, distribution, and reproduction in any medium, provided you give appropriate credit to the original author(s) and the source, provide a link to the Creative Commons license, and indicate if changes were made.

\section{REFERENCES}

1. Ferlito A, Rinaldo A. Paraneoplastic syndromes in patients with laryngeal and hypopharyngeal cancers. Ann Otol Rhinol Laryngol. 2000;109:109-17.

2. Ferlito A, Rinaldo A. Paraneoplastic syndromes in patients with cancer of the larynx and hypopharynx. Ann Otol Rhinol Laryngol. 2007;116:502-13.

3. Agaimy A. Paraneoplastic syndromes. Semin Diagn Pathol. 2019;36:203-92.

4. Henry K. Paraneoplastic syndromes: definitions, classification, pathophysiology and principles of treatment. Semin Diagn Pathol. 2019;36:204-10.

5. Ferlito A, Friedmann I. Neuroendocrine neoplasms. In: Ferlito A, editor. Neoplasms of the larynx. Edinburgh: Churchill Livingstone; 1993. p. 169-205.

6. Mason WP, Graus F, Lang B, et al. Small-cell lung cancer, paraneoplastic cerebellar degeneration and the Lambert-Eaton myasthenic syndrome. Brain. 1997;120:1279-300.

7. Dalmau JO, Posner JB. Paraneoplastic syndromes. Arch Neurol. 1999;56:405-8.

8. Sillevis Smitt P, Grefkens J, de Leeuw B, et al. Survival and outcome in 73 anti-Hu positive patients with paraneoplastic encephalomyelitis/sensory neuronopathy. J Neurol. 2002;249:745-53.

9. Dropcho EJ. Update on paraneoplastic syndromes. Curr Opin Neurol. 2005;18:331-6.

10. Gandhi L, Johnson BE. Paraneoplastic syndromes associated with small cell lung cancer. J Natl Compr Canc Netw. 2006;4:631-8.

11. Ferlito A, Rinaldo A, Devaney KO. Syndrome of inappropriate antidiuretic hormone secretion associated with head and neck cancers: review of the literature. Ann Otol Rhinol Laryngol. 1997;106: 878-83.

12. Ferlito A, Shaha AR, Rinaldo A. Paraneoplastic syndromes in neuroendocrine neoplasms of the head and neck: have they an impact on prognosis? (Editorial). Acta Otolaryngol. 2001;121:756-8. 
13. Ferlito A, Rinaldo A, Bishop JA, et al. Paraneoplastic syndromes in patients with laryngeal neuroendocrine carcinomas: clinical manifestations and prognostic significance. Eur Arch Otorhinolaryngol. 2016;273:533-6.

14. Shamseer L, Moher D, Clarke M, et al. Preferred reporting items for systematic review and metaanalysis protocols (PRISMA-P) 2015: elaboration and explanation. BMJ. 2015;350:g7647.

15. Kurzrock R, Cohen PR. Cutaneous paraneoplastic syndromes in solid tumors. Am J Med. 1995;99: 662-71.

16. Oppolzer G, Schwarz T, Zechner G, Gschnait F. [Acanthosis nigrigans in squamous cell carcinoma of the larynx]. Z Hautkr. 1986;61:1229-37. (Article in German).

17. Khachemoune A, Yalamanchili R, Rodriguez C. Bazex syndrome (paraneoplastic acrokeratosis). Cutis. 2004;74:289-92.

18. Valdivielso M, Longo I, Suarez R, Huerta M, Lazaro P. Acrokeratosis paraneoplastica: Bazex syndrome. J Eur Acad Dermatol Venereol. 2005;19:340-4.

19. Laccourreye O, Laccourreye L, Jouffre V, Brasnu D. Bazex's acrokeratosis paraneoplastica. Ann Otol Rhinol Laryngol. 1996;105:487-9.

20. Bazex A, Salvador R, Dupré A, Christol B. Syndrome paranéoplasique à type d'hyperkératose des extrémités. Guérison après le traitement de l'épithélioma laryngé. Bull Soc Fr Dermatol Syphil. 1965;72:182.

21. Bazex J, El Sayed F, Sans B, Marguery MC, Samalens G. Acrokératose paranéoplasique de Bazex associée a une ichtyose acquise, des troubles de la pigmentation et un prurit: révélation tardive d'un néoplasme laryngé. Ann Dermatol Venereol. 1992;119:483-5.

22. Blanchet F, Leroy D, Deschamps P. Acrokératose paranéoplasique de Bazex. A propos de 8 cas. J Fr Otorhinolaryngol. 1980;29:165-72.

23. Colomb D, Reboul MC, Mauduit G, Forestier JY. Forme diffuse d'acrokératose paranéoplasique de Bazex révélatrice d'une récidive et de métastases d'un cancer de l'épiglotte antérieurement traité. Ann Dermatol Venereol. 1981;108:885-8.

24. Gaillard J, Haguenauer JP, Dubreuil C, Romanet P. Acrokératose de Bazex, syndrome paranéoplasique révélateur d'une métastase d'un cancer de la vallécule guéri localement à trois ans. J Fr Otorhinolaryngol. 1978;27:353-7.

25. Legros M, Kalis B, Brunetaud P, Longuebray A. Cancer pharyngo-laryngé et acrokératose de Bazex. Ann Otolaryngol Chir Cervicofac. 1977;94:47-52.
26. Miquel FJ, Zapater E, Vilata JJ, Gil MP, Garin L. Paraneoplastic acral hyperkeratosis: initial sign of laryngeal neoplasia. Otolaryngol Head Neck Surg. 1997; 117:S239-42.

27. Mounsey R, Brown DH. Bazex syndrome. Otolaryngol Head Neck Surg. 1992;107:475-7.

28. Plasencia DP, Lazarich JMC, Macias AR. Acrokeratosisparaneoplastica (Bazex syndrome) with ear manifestation. Mediterranean J Otol. 2005;1: 148-51.

29. Sarkar B, Knecht R, Sarkar C, Weidauer H. Bazex syndrome (acrokeratosisparaneoplastica). Eur Arch Otorhinolaryngol. 1998;255:205-10.

30. Aksu G, Karadeniz A. Cutaneous paraneoplastic syndrome (acrokeratosisparaneoplastica) preceding squamous cell carcinoma of the glottic larynx. N Z Med J. 2006;119:U2006.

31. Milewski C, Wieland W. Paraneoplastische Akrokeratose: M. Bazex Eine tumorspezifische Dermatose bei Plattenepithelkarzinomen im KopfHalsbereich. HNO. 1988;36:158-60.

32. Wareing MJ, Vaughan-Jones SA, McGibbon DH. Acrokeratosisparaneoplastica: Bazex syndrome. J Laryngol Otol. 1996;110:899-900.

33. Hodge L, Marsden RA, Black MM, Bhogal B, Corbett MF. Bullous pemphigoid: the frequency of mucosal involvement and concurrent malignancy related to indirect immunofluorescence findings. Br J Dermatol. 1981;105:65-9.

34. Balestri R, Magnano M, La Placa M, et al. Malignancies in bullous pemphigoid: a controversial association. J Dermatol. 2016;43:125-33.

35. Bonnetblanc JM, Bernard P, Fayol J. Dermatomyositis and malignancy: a multicenter cooperative study. Dermatologica. 1990;180:212-6.

36. Mackenzie AH, Scherbel AL. Connective tissue syndromes associated with carcinoma. Geriatrics. $1963 ; 18: 745-53$.

37. Guin JD, Elleman JH. Yellow nail syndrome. Possible association with malignancy. Arch Dermatol. 1979;115:734-5.

38. Haines D. Primary carcinoma duplex associated with tylosis. J R Nav Med Serv. 1967;53:75-8.

39. Batinac T, Kujundzić M, Peternel S, Cabrijan L, Troselj-Vukić B, Petranović D. Pityriasis rubra pilaris in association with laryngeal carcinoma. Clin Exp Dermatol. 2009;34:e917-9. 
40. Nyati A, Kalwaniya S, Jain S, Soni B. Sign of LeserTrélat in association with laryngeal carcinoma. Indian J Dermatol Venereol Leprol. 2016;82:112.

41. Soga J. Carcinoids and their variant endocrinomas. An analysis of 11842 reported cases. J Exp Clin Cancer Res. 2003;22:517-30.

42. Soga J. Early-stage carcinoids of the gastrointestinal tract: an analysis of 1914 reported cases. Cancer. 2005;103:1587-895.

43. Soga J, Yakuwa Y, Osaka M. Carcinoid syndrome: a statistical evaluation of 748 reported cases. J Exp Clin Cancer Res. 1999;18:133-41.

44. Ferlito A, Rinaldo A. The spectrum of endocrinocarcinomas of the larynx. Oral Oncol. 2005;41:878-83.

45. Ferlito A, Devaney KO, Rinaldo A. Neuroendocrine neoplasms of the larynx: advances in identification, understanding and management. Oral Oncol. 2006;42:770-88.

46. Baugh RF, Wolf GT, Lloyd RV, McClatchey KD, Evans DA. Carcinoid (neuroendocrine carcinoma) of the larynx. Ann Otol Rhinol Laryngol. 1987;96: 315-21.

47. Kumai M, Arakawa T, Nakane T, et al. Serum serotonin elevated carcinoid tumor of the larynx (in Japanese). Larynx Jpn. 1996;8:53-5.

48. Overholt SM, Donovan DT, Schwartz MR, Laucirica R, Green LK, Alford BR. Neuroendocrine neoplasms of the larynx. Laryngoscope. 1995;105:789-94.

49. Wenig BM, Gnepp DR. The spectrum of neuroendocrine carcinomas of the larynx. Semin Diagn Pathol. 1989;6:329-50.

50. Yamanaka J, Yao K, Kohno H. A case of primary laryngeal carcinoid with the carcinoid syndrome and rapid clinical course (in Japanese). Kitasato Med. 1997;27:110-3.

51. Imura $H$, Matsukura $S$, Yamamoto $H$, Hirata $Y$, Nakai Y. Studies on ectopic ACTH-producing tumors. II. Clinical and biochemical features of 30 cases. Cancer. 1975;35:1430-7.

52. Bishop JW, Osamura RY, Tsutsumi Y. Multiple hormone production in an oat cell carcinoma of the larynx. Acta Pathol Jpn. 1985;35:915-23.

53. Schwartz WB, Warren B, Curelop S, Bartter FC. A syndrome of renal sodium loss and hyponatremia probably resulting from inappropriate secretion of antidiuretic hormone. Am J Med. 1957;23:529-42.
54. Kandylis KV, Vasilomanolakis M, Efremides AD. Syndrome of inappropriate antidiuretic hormone secretion in pyriform sinus squamous cell carcinoma. Am J Med. 1986;81:946.

55. Moses AM, Miller M, Streeten DHP. Pathophysiologic and pharmacologic alterations in the release and action of ADH. Metabolism. 1976;25:697-721.

56. Roth Y, Lightman SL, Kronenberg J. Hyponatremia associated with laryngeal squamous cell carcinoma. Eur Arch Otorhinolaryngol. 1994;251:183-5.

57. Talmi YP, Hoffman HT, McCabe BF. Syndrome of inappropriate secretion of arginine vasopressin in patients with cancer of the head and neck. Ann Otol Rhinol Laryngol. 1992;101:946-9.

58. Zohar Y, Talmi YP, Finkelstein Y, Nobel M, Gafter U. The syndrome of inappropriate antidiuretic hormone secretion in cancer of the head and neck. Ann Otol Rhinol Laryngol. 1991;100:341-4.

59. Trotoux J, Glickmanas M, Sterkers O, Trousset M, Pinel J. Syndrome de Schwartz-Bartter: révélateur d'un cancer laryngé sousglottique à petites cellules. Ann Otolaryngol Chir Cervicofac. 1979;96:349-58.

60. Takeuchi K, Nishii S, Jin CS, Ukai K, Sakakura Y. Anaplastic small cell carcinoma of the larynx. Auris Nasus Larynx. 1989;16:127-32.

61. Myers TJ, Kessimian N. Small cell carcinoma of the larynx and ectopic antidiuretic hormone secretion. Otolaryngol Head Neck Surg. 1995;113:301-4.

62. Mundy GR. Ectopic production of calciotropic peptides. Endocrinol Metab Clin N Am. 1991;20: 473-87.

63. Mundy GR, Ibbotson KJ, D'Souza SM, Simpson EL, Jacobs JW, Martin TJ. The hypercalcemia of cancer: clinical implications and pathogenic mechanisms. N Engl J Med. 1984;310:1718-27.

64. Plimpton $\mathrm{CH}$, Gellhorn A. Hypercalcemia in malignant disease without evidence of bone destruction. Am J Med. 1956;21:750-9.

65. Angel MF, Stewart A, Pensak ML, Pillsbury HRC, Sasaki CT. Mechanisms of hypercalcemia in patients with head and neck cancer. Head Neck Surg. 1982;5:125-9.

66. Zhang R, Li J, Assaker G, et al. Parathyroid hormone-related protein (PTHrP): an emerging target in cancer progression and metastasis. Adv Exp Med Biol. 2019;1164:161-78.

67. Minotti AM, Kountakis SE, Stiernberg CM. Paraneoplastic syndromes in patients with head and neck cancer. Am J Otolaryngol. 1994;15:336-43. 
68. Trousseau A. Phlegmasia alba dolens. Clinique Medicale de l'Hôtel-Dieu de Paris, vol. 3. London: New Sydenham Society; 1865.

69. Evans TRJ, Mansi JL, Bevan DH. Trousseau's syndrome in association with ovarian carcinoma. Cancer. 1996;77:2544-9.

70. Sack GH Jr, Levin J, Bell WR. Trousseau's syndrome and other manifestations of chronic disseminated coagulopathy in patients with neoplasms: clinical, pathophysiologic, and therapeutic features. Medicine (Baltimore). 1977;56:1-37.

71. Nikšic M, Balogh M. Über Gerinnungsstörungen bei Kehlkopf- und Rachen-Malignomen. Laryngorhinootologie. 1976;55:414-9.

72. Naschitz JE, Yeshurun D, Eldar S, Lev LM. Diagnosis of cancer-associated vascular disorders. Cancer. 1996;77:1759-67.

73. Liu PG, Jacobs JB, Reede D. Trousseau's syndrome in the head and neck. Am J Otolaryngol. 1985;6: 405-8.

74. Garcin R, Lapresle J. Sur un cas d'atrophie cérébelleuse corticale subaigue en relation avec un épithélioma du larynx. Arch Pathol. 1956;62:399-402.

75. Müller E, Spanke O, Lehmann I. Neurogene Störungen bei extrazerebralen Malignomen. Med Klin. 1969;64:1470-5.

76. Baloh RW. Paraneoplastic cerebellar disorders. Otolaryngol Head Neck Surg. 1995;112:125-7.

77. Cher LM, Hochberg FH, Teruya J, et al. Therapy for paraneoplastic neurologic syndromes in six patients with protein A column immunoadsorption. Cancer. 1995; 75:1678-83.

78. Garcia FJ, Blazquez JA, Perez-Moro E, Martinez S. [Paraneoplastic ataxia due to laryngeal carcinoma]. Acta Otorrinolaringol Esp. 1998;49:414-5. (Article in Spanish).

79. Lambert E, Eaton L, Rooke E. Defect of neuromuscular conduction associated with malignant neoplasm. Am J Physiol. 1956;187:612.

80. Eaton LM, Lambert EH. Electromyography and electric stimulation of nerves in diseases of motor unit: observation on the myasthenic syndrome associated with malignant tumors. JAMA. 1957;183: 183-99.

81. Gray TC, Halton J. Idiosyncracy to d-tubocurarine chloride. Br Med J. 1948;1:784-6.
82. Seute T, Leffers P, ten Velde GP, Twijnstra A. Neurologic disorders in 432 consecutive patients with small cell lung carcinoma. Cancer. 2004;100:801-6.

83. Fontanel J-P, Betheuil MJ, Sénéchal G, Haguenau M. Un cas de syndrome de Lambert-Eaton secondaire à un épithélioma laryngé. Ann Otolaryngol Chir Cervicofac. 1973;90:314-7.

84. Medina JE, Moran M, Goepfert H. Oat cell carcinoma of the larynx and Eaton-Lambert syndrome. Arch Otolaryngol. 1984;110:123-6.

85. Ferroir JP, Hervier-Caen C, Reignier A, Nicolle MH, Guillard A. [Remission of Lambert-Eaton syndrome over a 10-year period. Recurrence without evidence of tumor at autopsy]. Rev Neurol (Paris). 1989;145: 851-2. (Article in French).

86. Shipley E, Krim E, Deminière C, Lagueny A. [Lambert-Eaton myasthenic syndrome associated with vocal cord carcinoma]. Rev Neurol (Paris). 2008;164:72-6. (Article in French).

87. Wymenga AN, Slebos DJ, van der Naalt J, van Putten JW, Peters FT. [Abdominal complaints and neurological symptoms as an early sign of lung cancer: a manifestation of the anti-Hu syndrome]. Ned Tijdschr Geneeskd. 2003;147:616-9. (Article in Dutch).

88. Baijens LW, Manni JJ. Paraneoplastic syndromes in patients with primary malignancies of the head and neck. Four cases and a review of the literature. Eur Arch Otorhinolaryngol. 2006;263:32-6.

89. Erro Aguirre ME, Gila L, Olaziregui O. [Paraneoplastic sensory neuropathy associated with squamous cell carcinoma of the larynx]. Neurologia. 2016;31:286-8. (Article in Spanish).

90. Stummvoll GH, Aringer M, Machold KP, Smolen JS, Raderer M. Cancer polyarthritis resembling rheumatoid arthritis as a first sign of hidden neoplasms. Report of two cases and review of the literature. Scand J Rheumatol. 2001;30:40-4.

91. Eggelmeijer F, Macfarlane JD. Polyarthritis as the presenting symptom of the occurrence and recurrence of a laryngeal carcinoma. Ann Rheum Dis. 1992;51:556-7.

92. Cabane J, Lebas J, Wattiaux MJ, Imbert JC. [PseudoStill disease and neoplasm. 2 cases]. Rev Med Interne. 1988;9:81-4. (Article in French).

93. Cohen PR. Hypertrophic pulmonary osteoarthropathy and tripe palms in a man with squamous cell carcinoma of the larynx and lung. Report of a case and review of cutaneous paraneoplastic syndromes associated with laryngeal and 
lung malignancies. Am J Clin Oncol. 1993;16: 268-76.

94. Bataller L, Dalmau J. Neuro-ophthalmology and paraneoplastic syndromes. Curr Opin Neurol. 2004;17:3-8.

95. Parc CE, Azan E, Bonnel S, Sahel JA, Kaplan J, Thirkill CE. Cone dysfunction as a paraneoplastic syndrome associated with retinal antigens approximating 40 kiloDalton. Ophthalmic Genet. 2006;27: 57-61.

96. Hill CL, Zhang Y, Sigurgeirsson B, et al. Frequency of specific cancer types in dermatomyositis and polymyositis: a population-based study. Lancet. 2001;357:96-100.

97. Sahu R, Rathaur BP, Chaudhari TS, Shukla R, Malhotra KP. Laryngeal carcinoma presenting as polymyositis: a paraneoplastic syndrome. Ann Indian Acad Neurol. 2016;19:150-1.
98. Rubisz-Brzezinska J, Zebracka T, Musialowicz D. Coexistence of 2 paraneoplastic syndromes-acrokeratosis Bazex and Leser-Trèlat syndrome-in a case of squamous-cell laryngeal cancer. Przegl Dermatol. 1983;70:205-8.

99. Ehmann LM, Grahovac M, Kramer M, Ruzicka T, Wollenberg A. Paraneoplastic palmoplantar hyperkeratosis. Minor form of acrokeratosis neoplastica Bazex? Hautarzt. 2012;63:477-9.

100. Tsvetkov EA. [Dermatomyositis as a complication of the radiotherapy of laryngeal cancer]. Med Radiol (Mosk). 1977;22:78-9. (Article in Russian).

101. Zhang W, Jiang SP, Huang L. Dermatomyositis and malignancy: a retrospective study of 115 cases. Eur Rev Med Pharmacol Sci. 2009;13:77-80.

102. Maxwell EL, Witterick IJ. Syndrome of inappropriate antidiuretic hormone in a patient with metastatic supraglottic cancer. J Otolaryngol. 2004;33: 308-9. 